Skip Level Leadership Dynamics

\title{
SEEKING TRANSPARENCY WHILST EMBRACING AMBIGUITY \\ SKIP LEVEL LEADERSHIP DYNAMICS DURING STRATEGIC CHANGE
}

\begin{abstract}
Zahira Jaser
University of Sussex Business School

This paper is the recipient of the Best Paper Award from the Organizational Development and Change Division at the Academy of Management, 2018
\end{abstract}

\begin{abstract}
Extant, literature shows that it is important for leaders to create clarity and transparency to foster trust with their followers but also that it is important for leaders to construct slightly different meanings for each audience they face, to ensure buy-in for strategy implementation. This paper illuminates how these two contradictory dimensions of leadership coexist within a senior team in a financial institution, during the implementation of strategic change. A two years study of a multilevel team, formed by top, senior- and lower-level managers, uncovers the dynamics through which meanings are constructed through upward and downward sensemaking and sensegiving. Different leadership dynamics emerge, formal and skip level. Skip level leadership dynamics are characterized by junior managers and top manager enter in direct leadership relationships, bypassing the senior manager, in search for greater transparency. In doing so they disrupt the formal leadership relationship with the senior managers, affecting their leadership identity through sensebreaking. The temporality of this study allows to unveil that skip level leadership can be unsustainable, and tend to revert to formal leadership, favoring the existence of pragmatic ambiguity, where meaning construction is controlled by the senior managers mediation. Controlled attempts to create direct communication between top and junior managers are created, but only provide an illusion of transparency.
\end{abstract}

Keywords: strategic change; skip level leadership; sensemaking; sensebreaking; finance. 


\section{INTRODUCTION}

This paper explores how multilevel leadership relationships (Fairhusrt \& Uhl-Bien, 2012; Uhl-Bien \& Ospina, 2012; Fairhurst, 2016), and meaning construction (Pratt, 2000; Weick, Sutcliffe \& Obstfeld, 2005) unfold inextricably, in a senior management team, during strategic change. It aims to illuminate how leadership relationships and flows of sensemaking, and sensegiving, interpolate each other, at a time of ambiguity, as managers crave for more transparency and greater clarity (Vogelgesang, Leroy, Avolio, 2013; Schnackenberg \& Tomlinson, 2016). Both leadership dynamics and meaning making dynamics, such as sensemaking (i.e. the co-constructed interpretations of events, amongst organizational constituents; Weick et al., 2005) and sensegiving (i.e. the process of attempting to influence the sensemaking and meaning construction of others; Gioia \& Chitapeddi, 1991: 442) underpin how information is handled in organizations. Therefore, it is interesting to appraise both dynamics jointly and analyze how they reciprocally influence one another.

The way information is handled in organizations has consequences, for the organizations themselves and society at large; for example, a more transparent handling of information is advisable, as poor quality of shared information amongst organizational members' (Schnackenberg \& Tomlinson, 2016:1788) was identified as one of the systemic elements at the root of the recent global financial crisis (Ashby, 2011). Unsurprisingly, the leadership literature recognizes that the capacity to be clear and unambiguous is essential to the achievement of effective leadership outcomes (Vogelgesang, Leroy, Avolio, 2013), and to the formation of relationship of trust between leaders and followers (Graen \& Uhl-Bien, 1995) especially during situations of change (Norman, Avolio, Luthans, 2010).

Organizational leader's success depends also on their capacity to 'be forthright about the motives and the reasons behind the information given, and the decisions taken' (Vogelgesang, Lester, 2009:253). 
However ambiguous information is a fact of life in organizations too. 'To deal with ambiguity interdependent people search for meaning, [and] settle for plausibility’ (Weick, Sutcliffe and Obstfeld, 2005:419). Leaders' success has in part been ascribed to their capacity to embrace ambiguous information and translate it to different audiences they relate to (Corley \& Gioia, 2004; Sonenshine, 2010). The consequence is that leaders offer slightly different, or partial version of the same event to their followers, and to their own bosses (Rouleau, 2005; Huy, 2011; Huy, Corely, Kraatz, 2014), or to different stakeholders (Balogun, Bartuneck, Do, 2015), depending on the objectives they want to achieve. They do it to turn ambiguity in inter-relational certainties, that underpin trust, fundamental to high quality relationships between leader and follower (Graen \& Uhl-Bien, 1995). In fact, embracing and translating ambiguous information is an indispensable leadership practice (Fairhurst \& Uhl-Bien, 2012), for the successful roll out of organizational change and for the implementations of new strategy (Gioia \& Chittipeddi 1991).

So extant, literature shows that on one hand, it is important for leaders to create clarity and transparency to foster trust with their followers (Graen \& Uhl-Bien, 1995; Norman, Avolio, Luthans, 2010); on the other, that it is important for leaders facing different audiences, to construct slightly different meanings suitable to each audience (Balogun et al., 2015). These conflicting substantiations prompt the question at the base of this paper: how do managers embrace transparency, important for establishing effective relationships with their boss and their reports, whilst maintaining ambiguity, by creating slightly different interrelational understanding of events in adjoining relationships?

Hence, in order to expand our theoretical understanding of leadership relationships and meaning construction, I explore leadership as a multilevel process (Fairhusrst \& UhlBien, 2012; Fairhurst, 2016) unfolding across the hierarchical structure, zooming into the role played by senior managers, interfacing a top manager, and some junior managers. I study 
leadership dynamics through a case history, in which multiple interviews, field notes, archival records, and observations, provide a composite account of events that is the data of the analyses (Sonenshein, 2010; Fairhurst, 2016). This article therefore focuses closely into the sensemaking flows up and down the hierarchy (Balogun et al., 2015) and examines the accounts of leaders and followers in a senior management team in charge of the risk management of one of the largest financial institutions in the world. The research is conducted during more than two years at the time of the implementation of new global risk management system, therefore at a time of pervasive organizational change.

This paper is structured in four sections. First I provide a conceptual background reviewing the literature on transparency, and ambiguity during change, focusing on the role played by leadership and sensemaking. Second, by following the tradition of grounded theory (Corbin \& Straus, 1990; Corley \& Gioia, 2004) I give a rich description of the empirical settings, and the sources of data; here I present the data structure summarizing the categories emergent from the coding of the words of my informants. Third, I present the findings, by showcasing a dynamic model depicting the relationships between the categories, and the high level themes emergent from the data. In this finding section I exhibit how senior managers perpetuate systemic ambiguity through formal leadership dynamics. A major contribution come from the theorization different types of skip level leadership dynamics (free and controlled), and how they interact differently with the core formal leadership dynamics. Free skip level leadership, in which junior and top managers engage in direct leadership exchanges and meaning interpretations, destabilizes formal leadership relationships, by disintermediating the senior manager. Whilst controlled skip level leadership, where senior managers have the last say on the meaning construction, creates the illusion of greater transparency, but perpetuate the existence of ambiguity. 


\section{CONCEPTUAL BACKGROUND}

\section{Transparency, Ambiguity and Leadership Relationships During Change}

Broadly, transparency has been defined as the 'perceived quality of internally shared information from a sender' (Schnakenmberg \& Tomlinson, 2016, p.1788). Transparency therefore lies in the eye of the beholder. So in defining leadership as a relationship between a leader and a follower (Graen \& Uhl-Bien, 1995; Uhl-Bien, 2006; Fairhurst \& Uhl-Ben, 2012; Uhl-Bien et al., 2014), transparency is the followers' perception that a leader listens, and exhibits open communication (Vogelgesang et al., 2009), and vice versa. Transparency in communication has been recognized as an important dimension of leadership in organizations by practitioners (Pagano and Pagano, 2004), and academics alike (Gardner, Avolio, Luthans, May \& Walumbwa, 2005; Shamir \& Eilan, 2005; Norman et al., 2010). Transparent leadership behaviours are characterized by the extent to which managers exhibit openness in sharing information, acceptance of others' inputs, and of disclosure of personal values and motives in making decisions (Norman et al., 2010). For effective relationships to take place, leader and followers are therefore both entrusted with the responsibility to act with transparency (Grahen \& Uhl-Bien, 1995; Gardner et al., 2005; Shamir \& Eilan, 2005; Sparrowe, 2005).

However, transparency in communication might be a utopic attainment on the part of leader and follower. Ambiguity, defined as the quality of events, or communications, that are 'capable of being understood in two or more possible senses or ways 1 ' is a pervasive phenomenon, especially during change, where the status quo is unsettled, and there is not yet a clear idea of what the future will be like (Lewis, 2000). For example, in situations of strategic change, managers who act in pivotal positions, facing different stakeholders, have been found to use 'strategic ambiguity' (Eisenberg, 1984) in their favor by constructing

\footnotetext{
${ }^{1}$ Merriam-Webster on line dictionary definition, as retrieved on $8^{\text {th }}$ Nov 2017.
} 
slightly different meanings, about the same events, with different stakeholders (Corley \& Gioia, 2004; Balogun, et al., 2015) to achieve a 'unified diversity' (Eisenberg, 1984). More specifically senior managers, have been found to construct two 'sets of interwoven and interacting change narratives [in order to] mediate the relationship between the wider organizational change and local change actions' (Balogun, et al., 2015: 960). In this dual exercise they embrace multiple, even equivocal, interpretations of change, with different actors, in an attempt to rally different audiences around common objectives (Sonenshine, 2010; Harding, Lee and Ford, 2014; Balogun et al., 2015). In these situations attaining transparency might be problematic, or even damaging to the purpose of maintaining different interpretations in order to rally a specific audience. It is not clear, therefore how leader and follower maintain high quality relationships in the presence of this systemic ambiguity.

\section{Dealing with Ambiguity: Leadership and Sensemaking}

To deal with ambiguity senior managers, search for meanings with the people they interrelate with, up and down the hierarchical lines (Weick, et al., 2005; Balogun et al, 2015). With each actor they construct 'plausible meanings and move on: these are moments of sensemaking' (Weick, et al. 2005:419). As seen above, in the context of change, senior managers, leaders (to more junior managers), and followers (to the top manager), 'construct two sets of narratives as they attempt to make sense of their experience of change at any given time. The first set is about the wider organization change initiative of which they are recipients. The second set is about their local setting, for which they are the change agents' (Balogun et al., 2015:974).

Therefore, when exploring how ambiguity is dealt with, in the context of strategic change, the sensemaking and the leadership theoretical lenses are interlaced. They both evoke the fluidity of iterative exchanges, rooted in language and action, evolving through time. On one hand leadership is defined as the co-construction of relationships, identities and meanings 
between two actors, a leader and a follower, who mutually influence each other (Uhl-Bien et al., 2014; Uhl-Bien, 2006). Leader and follower are depicted to co-construct: relationships, through iterative processes of communication and action (Graen \& Uhl-Bien, 1995); common accounts of events, through contextually specific discursive exchanges (Fairhurst \& Grant, 2010; Fairhurst \& Uhl-Ben, 2012); or even, each other's identities, through individual, relational and collective, actions of claiming and granting (De Rue \& Ashford; 2010). On the other hand the process of sensemaking and sensegiving is also represented by a fluid iterative process, retrospective in nature, based on social interaction, between members of an organization, (Weick, 1995; Weick, et al., 2005). It is iterative and cyclical talks, where interpretation shapes actions and generates influence on to others (Rouleau \& Balogun, 2011:955). Further it affects mental models of reality, having a deep effect on the formation of organizational actors' identities (Weick, et al. 2005; Pratt; 2000).

In order to understand how these competing leadership dynamics, one entailing the search of transparency, the other the endorsement of ambiguity, co-exist in organizations I have explored the accounts leadership and sensemaking in a risk management team during the implementation of strategic change at MoneyManager. Plc., one of the largest financial institutions in the world.

\section{EMPIRICAL SETTINGS AND METHODS}

This study is based on a two years research project, following the principles of grounded theory (Corbin and Straus, 1990). By adopting a qualitative methodology in the study of leadership relationships and leadership dynamics I also address recent calls for more qualitative studies of leadership in context (Fairhurst \& Uhl-Bien, 2012; Fairhurst, 2016). 


\section{Empirical Settings Selection}

This study took place at MoneyManager ${ }^{2}$, which was a member of the FTSE500 share index, a global financial company with revenues larger than US\$20bn. The company, was headquartered in the UK, but had a world wide reach. MoneyManager Plc. offered wide range of financial services and was divided in several departments, each dedicated to a different segment of clients, or internal function. This research initially spanned different departments, but eventually focused on one specific team, the Risk Management Team (RMT), responsible for the implementation of the operational risk management strategy globally (as illustrated in Figure 1). The key function of the Risk Management Team was to monitor and assist departments around the globe to detect and countervail operational risk ${ }^{3}$. The company wide operational risk team was composed of more than 500 employees, divided in 10 departments; they ultimately reported to 10 managing directors, hereby called senior managers (SMs), each in charge of a department (as illustrated in Figure 1). For each SMn the study extended to one of their junior managers (JMn), selected because they occupied key positions in the SMs' team, as described by their role in Figure 1. All the SMs, reported to the Global Head of Operational Risk, defined here as the top manager (TM). TM was only two reporting positions removed from the chief executive officer (CEO) of the entire organization; therefore, he was one of the most SMs in the company worldwide.

Sample Selection. In choosing the settings, I was guided by theoretical sampling (Glaser \& Strauss, 1967). First, at the industry level, large financial services are still considered amongst the most bureaucratic and hierarchical organizations (Knorr Cetina \& Preda, 2006), and highly hierarchical environments are particularly rich settings to explore dynamics of

\footnotetext{
2 All names of individuals and organizations are pseudonyms. In particular MoneyManager Plc. is the organization in which the study takes place. MoneyManagerReg is the financial regulator. MoneyManagerComp is a pseudonym for competitors as they appear in the informants' conversations.

3 This is different from market or credit risk, and it involves mistakes and events that disrupt everyday business, including for example, a failure to comply with regulation, a loss caused by poor, faulty, or hacked computer systems (cyber risk), and human error (conduct risk).
} 
multilevel vertical leadership relationships. Second, the study happened at a crucial time of strategic change, during the implementation of a project here code-named 'Shift'. 'Shift' entailed the replacement of the current risk monitoring systems globally in response to regulatory pressure by MoneyManagerReg (the financial regulator), requesting to improve the transparency of communication, of operational risk (Ashby, 2011).

Figure 1.

(Study at Phase 1) Studied sample highlighting roles, formal and skip level relationships

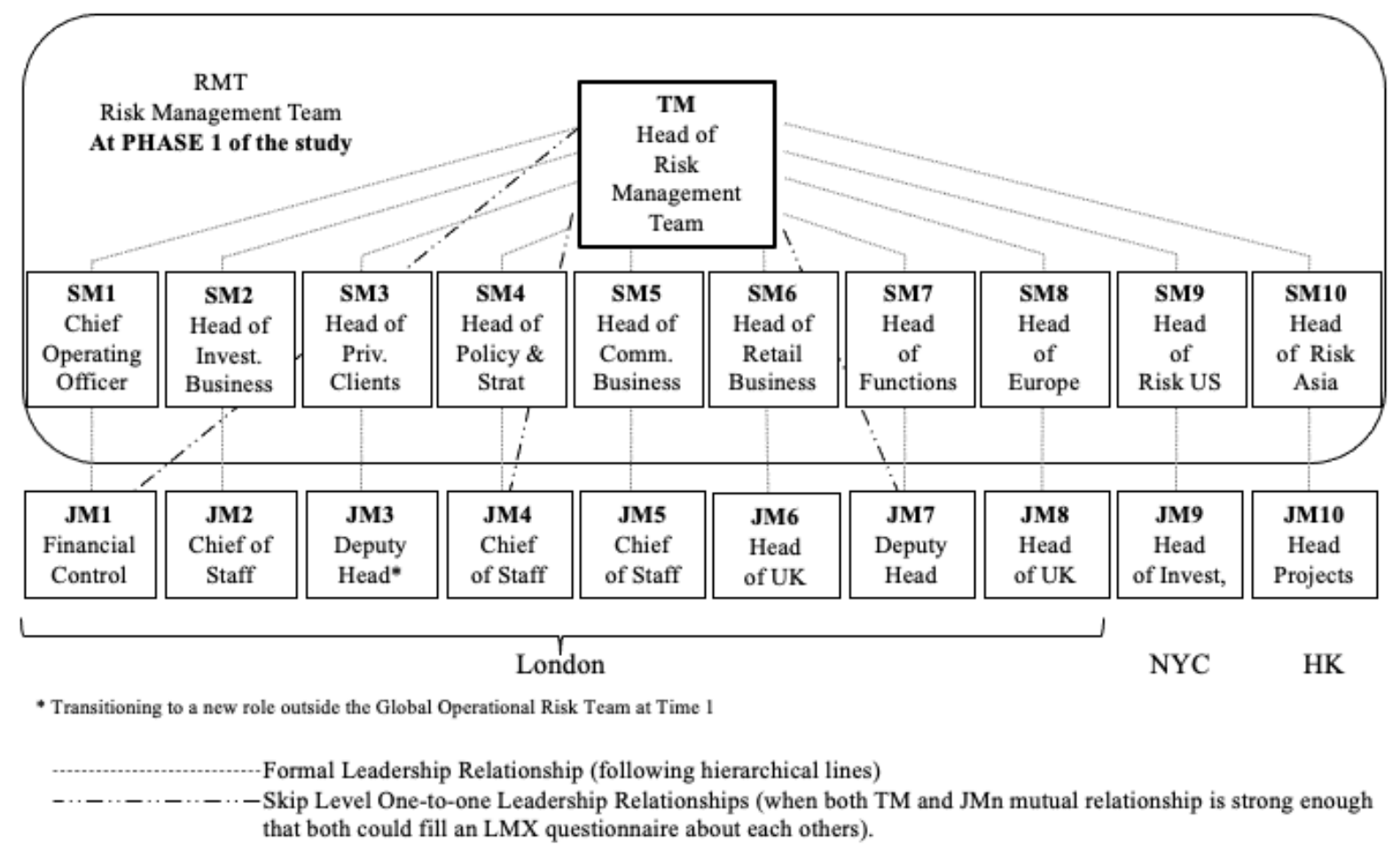

Strategic Change Overview. In order to implement 'Shift' a new Risk Management Team Head, the Top Manager (TM) was hired at the end of 2013. By the beginning of 2014, the new Risk Management Team was taking shape, with a new COO (SM1), and a new Global Strategy and Policies Officer (SM4). In 2014 the strategic change programme got the funding to go into a three years stage, and it was named project 'Shift'. The core objective was to introduce a new risk framework, and new systems for monitoring and recording operational risk, across 150,000 employees, and 2,000 offices worldwide. 


\section{Sources of Data}

This study includes real time and retrospective data, collected in more than 2 years, in 2 phases: Phase 1 when the decisions made by the RMT where starting to be implemented across the departments, and Phase 2 when the implementation of the change was drawing to an end. I used four data sources: interviews, observations, survey, and archival data. The data collection process is illustrated in Figure 2.

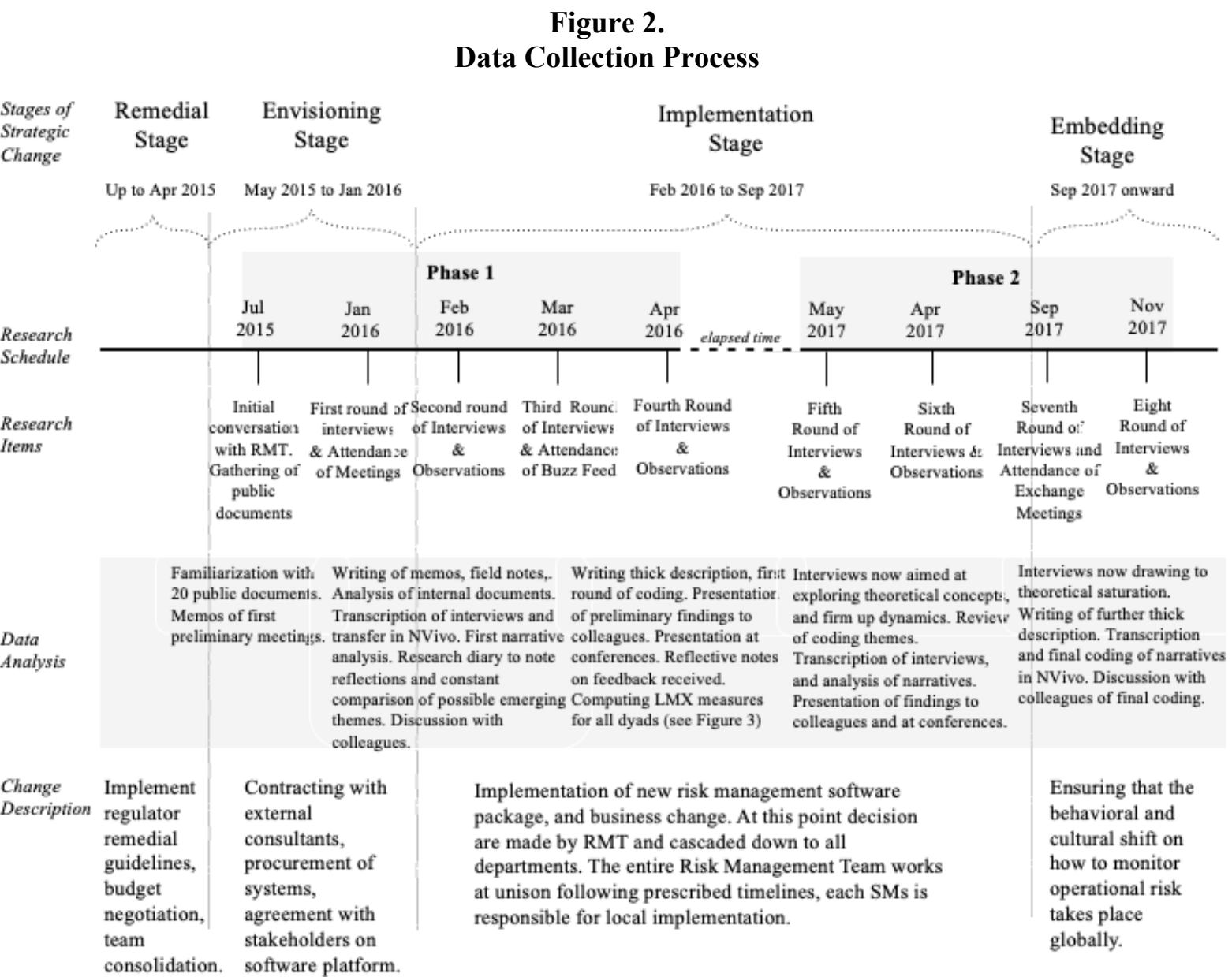

Interviews. I conducted 42 formal interviews (27 in Phase 1, and 15 in Phase 2) and additionally I had a series of informal and unofficial conversations during observations times, totaling more than 100 contact points with informants during the 24 months of the study.

Informal and unofficial conversations where promptly written down in the research notes. The majority of formal interviews (1h or more, recorded and transcribed) were with the TM (5), the SMs (18), and the JMs (14), 4 with project managers. I collected approximately 160,000 
words of formal interview data (circa 350 pages). I kept a disciplined approach, by enquiring about each manager in their role of leader and their role of follower.

Observations. I was allowed to attend and record meetings of the entire senior team, participate to 'Buzz Calls' (weekly conference calls for RMT), to 'Town Halls' (between the TM and a broad body of JMs), and 'Exchanges' (meeting for junior managers to 'voice' concerns to TM). I also measured the strength of relationships through leader-member exchange questionnaires (LMX-7, Graen and Uhl-Bien, 1995). I considered a leadership exchange existed only when both dyads' participants said there was sufficient perceived direct leadership exchange with the other party, so they could answer all questions of the questionnaire. As a result, only three TM-JMn dyads, revealed a direct leadership relationship between (JM1, JM4, JM7), as highlighted in Fig. 1. At Phase 2 I returned to examine how the leadership relationships had evolved, and the picture had changed, see Figure 3.

Archival Data. I reviewed many documents, including primary internal ones (5 strategy plans, several e-mails directives and 3 risk training presentations to staff), and public documents ( 5 press releases, 3 regulatory reports on the company, 5 annual reports, 12 web pages, 20 executive speeches), totaling many thousands of pages of material.

\section{Data Analysis}

The qualitative research process was iterative, allowing me to go from data to concepts, back to data during a period of change in the environment of the actors I was studying (Corbin and Strauss, 1990; Suddaby, 2006). I iteratively appraised the data as I collected it and analyzed it, compared it with other researchers, identified emergent themes, and then progressively explored them through existing theories, during the roll out of 'Shift'. Once the concepts had drawn to theoretical saturation, I drew some conclusive findings,-the data structure is illustrated in Figure 4, which summarizes the second order themes on which I built the model illustrating the leadership process (Figure 5). 
Figure 3.

(Study at Phase 2) Evolution of the studied sample, the people who left unexpectedly, JM1, JM4 and SM7, were all in skip level relationships

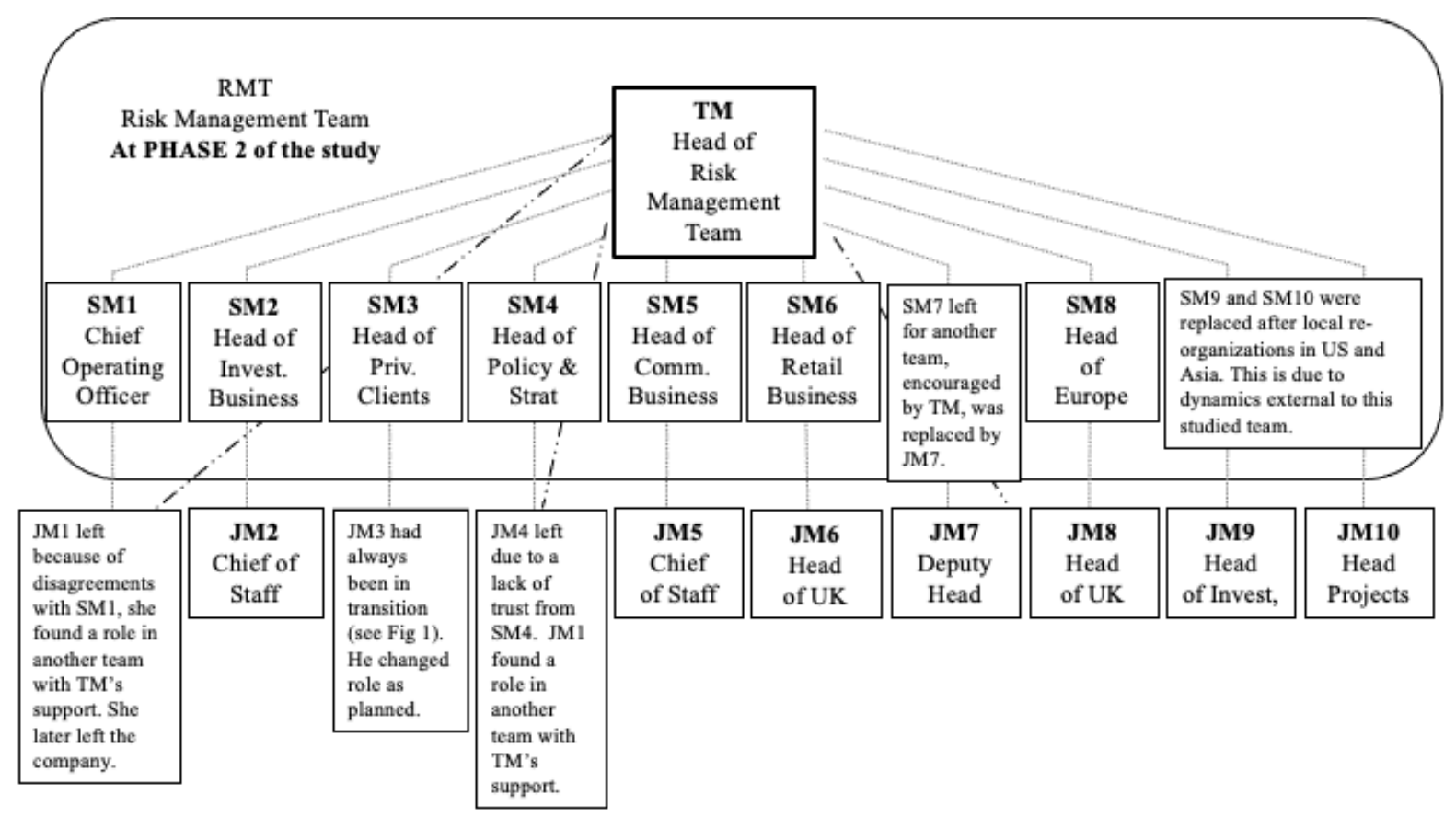

FINDINGS

The leadership accounts during change revealed how the managers in the RMT at MoneyManager, attempted to achieve greater transparency, whilst embracing ambiguity, through two leadership dynamics during the implementation of 'Shift'. These dynamics interacted with each other, and they are represented in Figure 5.

The first dynamic was dominated by a discourse of formal hierarchical leadership, which broadly endorsed ambiguity, and aimed at creating inter-relational clarities within each leader-follower dyadic relationships: SM-TM and SM-JM. The second process was dominated by discourses of skip level leadership (Detert \& Treviño, 2010), broadly aligned with a search for greater transparency, in which both managers at the top and at the bottom of the hierarchy were keen to skip reporting levels to seek further clarity of information. Skip level leadership dynamics emerged in two distinct typologies: free and controlled - see APPENDIX $1 \& 2$ for an extensive triangulation of data of these phenomena. Below I dive into each category, and how categories relate to each other. 
Figure 4.

Data Structure

\section{First Order Concepts}

Scan for ambiguity up the hierarchy

Identify implicit \& explicit agendas from direct leader and above

Challenge leader's agenda for clarity

Intrapersonal clarity creation and elaboration of a new explicit agenda (unwittingly forming an implicit one)

Frame the explicit agenda into stories for one own department

Co-construct meanings with followers to ensure alignment to leader's own agendas

Prize those whose execution is aligned to their direct leader's agendas Reprimand those who divert form leader's own agenda, by changing the message away from the co-constructed interpretation

$$
\begin{array}{cc}
\text { Second Order } & \text { Higher Order } \\
\text { Concepts } & \text { Themes }
\end{array}
$$

Interpretation \&

Influence of

Leaders' Agendas

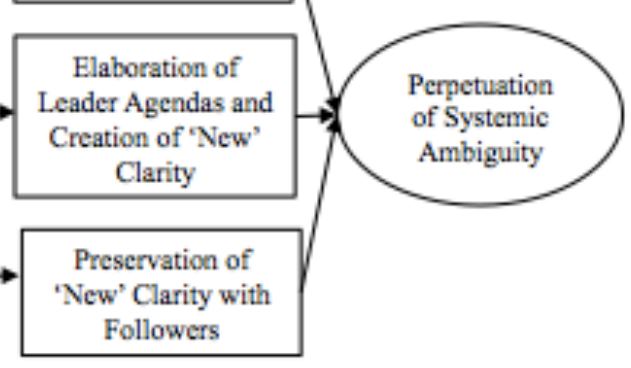

Independent leadership exchanges with a manager above own boss Consider exposure to upper level leader as aspirational and rewarding Spend one-to-one time with one's boss' boss, without line manager

Sensebreaking: Independently co-creation of meanings away from skipped leader, resulting in loss of role of mediator for senior manager Risk of being 'exposed' in front of own boss by the skip follower Lower ability for skipped leader to control follower's agenda

Senior manager losses control on meaning construction Senior manager reputation is tamished by skip level relationship exchange

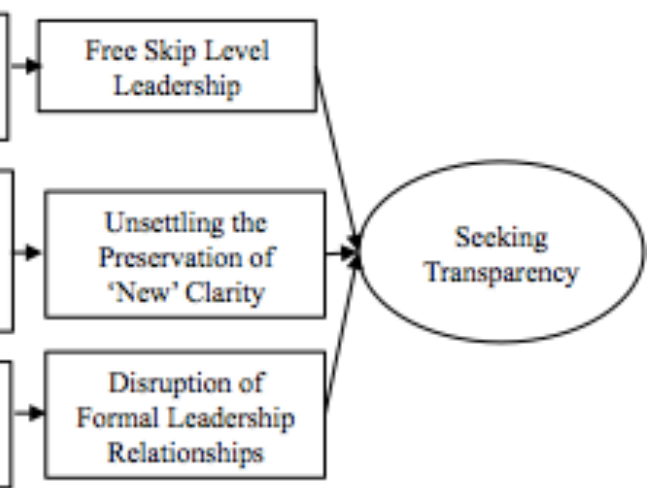

One-to-one skip level:

Skipped leaders control the relationship between their own follower and their own leader

The upper leader influences the skipped level leader's hiring process; Collective skip level:

Town Hall as a collective top down leadership tool for upper manager Exchanges, as a bottom up leadership tool connecting upper leader and lower followers.

Bounded Sensebreaking: Skipped leader knows that in the presence of ambiguous information the follower checks back and stick to their oconstructed meaning

Followers do not express themselves freely as they are afraid of skipped level, and higher level leaders reaction through 
Figure 5.

Dynamics of leadership and sensemaking that allow the coexistence of transparency and ambiguity

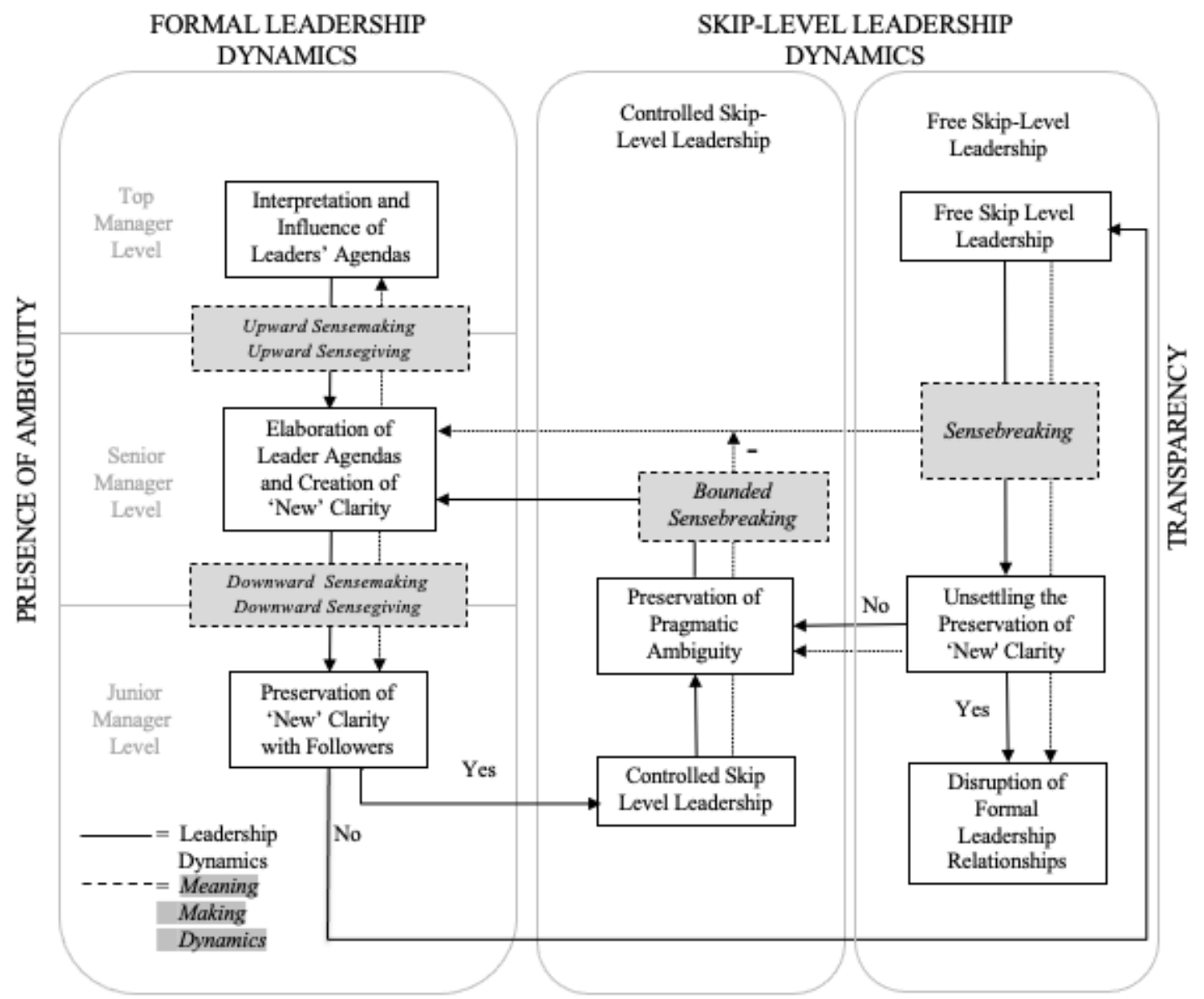

\section{THEME 1: Presence of Ambiguity (see more data in Table 1)}

'Shift' was a very high-stakes ${ }^{4}$, high-visibility ${ }^{5}$ project under the constant inspection of internal (MoneyManager CEO, CRO and shareholders), and external (MoneyManagerRegs and the press) high profile stakeholders. During my early interactions with the company at Phase 1, the account of the TM, when he spoke in his role as a leader, reflected a sense of

\footnotetext{
4 "The security of our information and technology infrastructure is crucial for maintaining our client services and protecting our customers and the MoneyManager brand. Work is ongoing to strengthen internal security controls and to prevent unauthorized access to our systems and network. We are also improving the controls and security applied to protect our customers. Strong engagement and support within the industry, government agencies and intelligence providers helps to ensure we keep abreast of developments" (doc-07c)

5 "Failure to implement our obligations under the US MoneyManagerReg could have a material adverse effect on our results and operations" (doc-07).
} 
clarity in purpose and mission, he felt he had agency in changing MoneyManager risk approach for the better:

So I am a custodian for the firm, to make it succeed over multi-generations, and not just [to be] a short time phenomenon... I work with the regulator quite a bit; I can actually help restore, through the regulator and with the actions here ['Shift'] ... some of the trust that society places in [financial institutions]. So I do feel there is a higher order of calling, vocational calling, of actually repairing the role of [financial institutions] ... Restoring faith in [financial institutions], and doing it in one of the biggest [financial institutions] in the world." (TM, int.01).

His struggle with ambiguity appeared when I enquired about him in his role as a follower to his superiors, about how he related to the $\mathrm{CRO}$ and the CEO. A different set of accounts emerged, as it appears in the words of SM1:

You will silently hear him saying: 'Oh, my God, MoneyManagerComp's CRO nearly got fired for bringing in a new system [like 'Shift'], we are putting in a new system, should we be putting in a new system?'. But sometimes he won't expressed that to me, you will just go off and have various conversations, and though he will come back and say: 'Actually we've all decided that we are not going to implement the system'. Whilst your regular course of action, you already convened all the stakeholders that are going to win the RFP [Request for Proposal] to a committed outcome. And he's got a little bit scared [to continue with a project], and then ... (SM1, int.02)

From the outset, I payed great attention to my informants' accounts in their role as leaders of their teams, and as followers of the upper management in the RMT.

\section{Perpetuation of Systemic Ambiguity}

Three specific discourses of formal leadership characterized my informants' experiences of dealing with ambiguous interpretations of events across leadership relationships: (1) interpretation and influence of leaders' agendas; (2) elaboration of leaders' agendas, and creation of a 'new' clarity; (3) preservation of the 'new' clarity with followers. In this findings presentation I have coordinated and integrated five data displays - the finding structure itself; figure 4, showing the progressive data structure; figure 5, showing the emergent model; Appendix 1, showing additional supporting data for each theme. This should facilitate the reader to navigate and appraise the evidence of my findings. 


\section{TABLE 1}

Data Supporting Formal Leadership Dynamics

\begin{tabular}{|c|c|}
\hline Theme & Representative Quotes \\
\hline \multicolumn{2}{|r|}{ THEME 1: Perpetuation of Systemic Ambiguity } \\
\hline $\begin{array}{l}\text { Interpretation } \\
\text { \& Influence of } \\
\text { Leaders' } \\
\text { Agenda }\end{array}$ & $\begin{array}{l}\text { - "[When I give my SMs information], they will seek clarification... you know. These are the } \\
\text { things, these are the issues they're seeing on the ground, you know... Sometimes they will use } \\
\text { their one to ones [meetings with me] to, you know, they'll have their own list of things they } \\
\text { want to talk about in a one to one, they'll have their own agenda." (TM, int. 01) } \\
\text { - "The execution of ['Shift'] was ambiguous... So the implementation of ['Shift'], the mandate } \\
\text { from TM originally was just go and get it done quicker, because it's all gone a bit slow and } \\
\text { doesn't need to be working... However none of us understood exactly what we had to do for } \\
\text { 'Shift'." (SM8, int.22) } \\
\text { - "[When that phase of the implementation of 'Shift' comes to us.] For me it is a lot about } \\
\text { predicting what TM will be challenging us on, and predict what challenges are and ask my } \\
\text { team those questions before they come to the table. Like any good manager should do with } \\
\text { their manager. (SM10, int.25) } \\
\text { - "So I will challenge TM. If he says let's go do X, or let's do Y, I will ask him why he's trying } \\
\text { to do that, and what the effect is that he's trying to achieve from that. Cause actually, if you } \\
\text { understand the effect, then you better understand what it is you're trying to achieve." (SM8, } \\
\text { int.12) }\end{array}$ \\
\hline $\begin{array}{l}\text { Elaboration of } \\
\text { upper agendas } \\
\text { and creation of } \\
\text { 'new' clarity }\end{array}$ & $\begin{array}{l}\text { - "And a lot of it I really didn't escalate to him (TM), I didn't discuss with him, because I was } \\
\text { trying to establish myself, anything actually that worked out okay, because I managed to a } \\
\text { number of deliverables which were coming through, you know, as part of what we had to do } \\
\text { for ['Shift']." (SM3, int.04) } \\
\text { - [SM2] is quite capable to create his own clarity in his mind from a number of complex } \\
\text { different inputs. I think providing clarity is something he does himself." (JM2, int07) } \\
\text { - "So I took the execution of ['Shift'], discussed it with my team. Got their input. And then I } \\
\text { elaborated it, and I took it back up to TM." (SM7, int.12) } \\
\text { - "I think successful leaders are about telling stories. ... Actually if you're going to influence } \\
\text { people, it is actually not about telling them everything you know, it's not about telling them the } \\
\text { facts, it's about engaging them in a story, which encompasses the relevant facts that they need } \\
\text { to know." (SM1, int.02) } \\
\text { - "I try to give them only the salient things of what matters, not the entire message, and if there } \\
\text { is any mandate changes we talk about it." (SM2, int.03) }\end{array}$ \\
\hline $\begin{array}{l}\text { Preserve } \\
\text { 'New' clarity }\end{array}$ & $\begin{array}{l}\text { - "[SM1] is able to, within the freedom I grant, to put her mark in terms of what she will do." } \\
\text { (TM, int. 01) } \\
\text { - "There is a huge amount of whitespace in that and what SM3 does, she takes that and she } \\
\text { paints the white bits beautifully. So she interprets some of the things I say she makes a } \\
\text { selection of the things that she can use you can't. And she does it well." (TM, int.01) } \\
\text { - "Where I think they're off, completely off course, and I'll stick them quite quickly." (TM, } \\
\text { int.17) } \\
\text { - "I know [TM] would probably kill me if I heard that [laughs]... because the } \\
\text { [MoneyManagerReg] said we don't do things consistently, right? ... but sometimes the tools } \\
\text { that we're given to do that are so generalist that actually we want to make it relevant to my } \\
\text { audience, to the [Private Client Business]. (SM3, int.10) } \\
\text { - "And SM2 would sometimes say that part of my role is that of "chief whip', getting them } \\
\text { [reportees to SM2] in order'... I try to get cohesion in what we are doing and what we are } \\
\text { articulating. (JM2, int.07) }\end{array}$ \\
\hline
\end{tabular}

Interpretation and Influence of Leader's Agenda. Most managers, including the TM, spent a

great part of the interviews speaking passionately about their tactics in interpreting and

influencing their bosses. Even the TM was clearly was scanning up the hierarchy in search for

clarity: 
It's probably the way I operate, I suppose. I am absolutely, um, trying to interpret, my bosses agenda. So there is an explicit agenda, and there is an implicit agenda... And I try to understand both... My radar tries to be switched on. Whether I'm as sophisticated as I'd like to be [I don't know]. But it absolutely tries to be. ... And I mean, less so in other places, but in finance in general, only the paranoid survive. There is a little bit of paranoia into this (TM, int. 01)

So whilst TM's accounts as a leader projected great agency to the point of being a 'custodian' of the firm, as a follower he gave an insightful description of his attempts of deciphering his bosses' hidden messages, to create greater clarity. Similar accounts of upward sensemaking were pervasive from SMs: SM6 (int.19) was keen to explore "what the nuances of that story are [from the top], and then work out the decision"; SM8 (int.12) interpreted and then checked back "so I've gone back to TM and said: 'This is the way I'm now going. Do you agree with where this is going?" At the same time SMs were trying to influence their leader, through a process of upward sensegiving. A strong example comes form how SM1 (int,02), the COO of RMT, described how she reassured doubts at the beginning of 'Shift': "I tried to get back to the rationale. Reminding him [TM] why we were [implementing 'Shift'] in the first place", or " [I told TM:] 'We all do everything in our power not to have a complete disaster." or "If-, if I am convinced in my heart that these are important outcomes to fight for I will tell TM." So SM1 played an important role in supporting TM in wading through ambiguity, and together they created inter-relational clarity at the level of their dyad. Undoubtedly SM1 helped TM create inter-relational clarity: "SM1 is a very good builder [in planning 'Shift']". Ambiguity arose also because the needs on the grounds were different for all the senior and JMs.

Therefore inter-relational clarity between top and SM needed to take into account department specific nuances for the implementation of 'Shift', and through upward sensegiving, SMs grounded the TM in their departments realities: SM2 grounded TM "in the perspective of someone in derivative settlement'(int.03), or one in Asia who convinced TM that they "will have to do it differently here" (JM10, int.27). Through the process of upward sensegiving the SM influenced the TM explicit and implicit agendas: "He-, he knows he can't 
articulate his agenda. And so I actually just help him with that articulation. It is, you know, making it conscious, rather than unconscious." (SM8, int.22) So from the perspective of the SM inter-relational clarity with the TM, was created through the dynamics of upward sensemaking and upward sensegiving, which produced a shared explicit agenda at their dyadic level with the TM.

Elaboration of upper agendas and creation of 'new' clarity. Managers operated as linking pins in the connection of the two dyadic clarities, with top and JMs, by forming their own interpretation of events: "then I elaborated it", "I combined it into a story", "I pieced it together", "the way my brain works, and I add value, is by taking lots of pieces and making it into a coherent story", or as the Head of Commercial Business put it:

So when [TM] talks to us at the op risk management board which is his directs' meeting [RMT] ... I take the messages to my team directly with the people who sit with me but also in my team meetings I have with my global team. I might put them into my own language and actually, I'm quite keen that I put direction to my team into my own words rather than just forwarding an email from [TM]. (SM5, int.18)

This process of 'ownership' was effectively a personal process of selection of meanings, or of explicit (and implicit) agendas. Clear agendas were instrumental to keep their followers focused on few, well-defined objectives, to 'shield them away from disparate messages", or from ambiguous information, "I want them to remain focused and motivated and not always exposed to the theatrics and challenges of the [top] management team" (SM2, int.03), or to ensure the message was understandable by a specific audience, so the content of some trainings about 'Shift' was framed 'it as stuff that is important to the people in the [Private Client Business]... an embellishment on it, is a critical requirement to make sure that it lands appropriately." (SM3, int.10). Formal leadership dynamics were instrumental for a 'new' clarity to emerge.

Preserve 'New' Clarity. The 'new' clarity had to be plausible to the senior and the JMs, in order to become inter-relational clarity. Hence it was co-constructed through a process of downward sensemaking too, through which senior and JMs engaged in interpretations of 
events related to 'Shift'. SMs engaged junior manages as they wanted them to be "part of the solution", or to "give them an opportunity to contribute", they though "that's important they get involved". Here discourses emerged as characterized by individual and collective pronouns, reflecting single managers personal control as intertwined with collective decisions. SMs used singular possessive pronouns, when talking about their downward team, "my team", when referring to their JMs, revealing this sense of belonging, shared goals, but also a sense of ownership and being in charge, and exercising leadership. Collective pronouns accentuated how they felt unity in constructing meanings with the JMs: "we [me and my JMs] sit down", "we say this is what we're trying to do", "how do we best get the message across". This reflected the cognitive individual and collective process of sensemaking and sensegiving through which SMs and JMs achieved inter-relational clarity. In creating the clarity the SM controlled the meaning construed with the JMs in a way that it was also true to the TM's agendas. Control emerged in two dominant discourses: one prizing those that stuck to the 'new' clarity, and another one reprimanding those who diverted from it, as it can be seen in Table 1. Therefore, in iterative dynamics of meaning construction (upward and downward sensemaking and sensegiving), the SMs as the linking pins, played a role of meaning 'clearings houses', by engaging in two leadership exchanges. This mediation perpetuated a sort of systemic ambiguity, as they shielded the JM from fully transparent access to upper information.

\section{THEME 2: Seeking Transparency (see more data in Table 2)}

The accounts of my informants, as well as my observations, and archival documents reflected two ways in which the top and JM tried to overcome this ambiguity, engaging in direct skip level leadership exchanges. The free skip level leadership (see APPENDIX 1 for triangulation on data on this phenomenon) dynamic worked as follows: first, it entailed an independent exchange, away from the control of the SM; second this leadership exchange had 





JM7's a survivor, and the most senior of the survivors. The ones that we [TM] trust. So he's been asked to think about, you know, what the model will be [for the implementation of 'Shift']. If for some reason that bridge goes away from SM7, he will want to come straight back into his previous place. And only, you know, in the last few weeks has seen that: 'Oh my goodness, I could be caught here. If I have to jump back, then there's a new relationship being established between one of my subordinates [JM7] and [TM]". (TM, int.17)

- "I didn't feel like it was my call, and it took a long time to eventually have to say to him: 'I know she's your friend, but it's not working.' Because I guess in the back of my mind, was he going to choose her over me? And that really wasn't clear. (SM1, int.34)

- "I'm very cautious, if I am discussing work matters with TM, I need to understand the impact I have... I stepped and gone around my middle management but it's how I choose to do it" (JM4, int.09)

the capacity to unsettle the 'new' clarity, as it disrupted, or over-rode, the elaboration and interpretation of the SM, through sensebreaking; third, it had the power to disrupt the dyadic relationship between senior and JM, when the SM felt his role of mediator of meaning, and his reputation as leader were jeopardized.

Free Skip level Leadership. Vertical leadership created bottlenecks for the sensemaking and sensegiving flows up and down the organization, as illustrated above. So a central theme in the process of meaning construction was represented by the propensity for junior and TM to skip the SM, in order to have greater clarity of information during the implementation of 'Shift'. JMs saw the exposure to the TM as aspirational and rewarding. A manager in the Private Client Business appreciated how exposure to TM would bring opportunities, they sat next to each other for dinner at an offsite meeting and "he then approached me for a couple of opportunities in Hong Kong", or other managers "totally appreciated he took the time to talk to [them] personally". Furthermore, at phase 1, three of the JMs' accounts portrayed free skip level leadership exchanges with the TM (JM1, JM4, JM7). These exchanges were characterized by such a frequency and intensity that both the junior and TM felt they could fill a questionnaire, about the quality of their leadership relationship ${ }^{6}$ (LMX-7, Graen, \& UhlBien, 1995), see Fig. 2. This was reflected in their accounts:

\footnotetext{
${ }^{6}$ Rating on a Likert scale from 1-5 their perceptions of: how satisfied they were with each other as leader or follower; how well their own leader (or follower) would understand their job needs; what were the chances that their leader (or follower) would bail them out at time of need, and so on.
} 
I have regular one-to-ones with [TM] directly, and I am the only [JM] in the RMTmeetings. And I have a direct one-to-one [meeting] with TM. So I always have a chance to tell him things. Also he treats me as his voice of reason. (JM1, int.05)

I have a direct relationship with TM, I know him from [MoneyManagerComp], if I see him at the coffee machine we can talk about anything. I'm going out for a beer with him next week just the pair of us. (JM4, int.09)

These free came alive in the accounts of my informants which detailed how these interactions meant that junior and top manager could create their own clarities.

Unsettling the Preservation of 'New' Clarity. When the top and JMs engaged in independent leadership exchanges, co-creating meanings separately from the SM, sensebreaking occurred, the practice of over-riding or 'destroying meanings' created by the skipped leader (Pratt, 2000; Mantere, Schildt, Sillince, 2012:174). Sensebreaking would disrupt the inter-relational clarity that the SM had built with both top and JM. This stands out clearly from the account of JM1:

But in the current situation she [SM1] just needs to accept that certain information I will tell TM and tell her both in the same way. She could not expect that sometimes I brief her and then she can brief him and then she can come back to me and another fine tuning and then she can go back to him right? It's redundant. Sometimes, time is of an essence, so we all sit on the same floor when I tell something to him as is going into a meeting I will brief him, I'm not going to book a meeting with her... sometimes making it formal breaks down the clarity of communication in my view. (JM1, int.05)

So, whilst the independent direct exchange between junior and TM increased clarity it also had a negative impact on the capacity of the SM to mediate meanings. In fact, free skip level leadership was viewed as "somewhat haphazard", and as the TM told me: "It can certainly increase anxiety for the person in the middle. I'm sure if I started to have fireside chats with [the CEO], it would cause anxiety to [the CRO]." Therefore, sensebreaking manifested itself in an "increase in anxiety" for the skipped leader, as his/her weaknesses, shortcomings, interpretations, or just explicit and implicit agendas could be exposed in the direct communication between JMs and TM. Direct communication between the top and the JM could "destroy the identity" of the skipped leader and cause a "loss of respect" from his/her followers (SM5; int.39). The risk was, in short that the JMs and TM created their own interrelational clarity, which would eliminate the need of the SMs' mediation, causing the latter a 
loss of role identity. This affected SMs ability to create and preserve interrelation clarity; it limited their role of mediator and controller of meanings; ultimately affecting their sense of self as leaders. This could have at times a profound effect on the skipped leader, it made them feel "anxious", "vulnerable", "cross" or "upset". The literature could not provide answers on dynamics of skip level leadership (Detert and Treviño, 2012), and its consequences. Therefore at Phase 2, I found how the team had evolved, and this evolution provided insights on the interaction between the two leadership dynamics.

Disruption of Formal Leadership Relationships. In Autumn 2017, TM came to one of our meetings glowing, with the news that his boss, the CRO, had just received a letter from MoneyManagerReg, confirming the success of 'Shift'. The letter stated that:

"We've gone from being in the penalty box and on probation with the regulator to being acknowledged to having turned it around. So now we're off probation... [we are now] fit for purpose, and some things [we]'re doing are over and above what the industry's doing." (TM, int.37).

The TM, who only eighteen months before had been afraid of causing his boss (the CRO) the loss of his job, had instead caused him to be praised directly from the regulator. However, he also told me that three managers had left unexpectedly between time 1 and time 2 . Aside from the two heads of Asia (SM10) and US (SM9), who had left because of changes and restructuring in the 'regions', the remaining three were all involved in free skip level leadership exchanges, as it is shown in figure 3, they were JM1, JM4 and SM7. The coding revealed how sensebreaking could lead to the unsettlement of formal dyadic leadership in two ways: (i) by overriding the SM capacity to control meanings, or (ii) by causing a loss of face of the SM. And ultimately by removing their raison d'etre as mediators of relationships.

Skipping a level was risky for a number of reasons. First, it exposed the skipped leader's leadership skills, to the judgment of their boss, "[when] the managers below [you] poorly represent what you are doing [to your boss] ... Then to certain extent that absolutely reflects on how they have been led by you (laughs)" (TM, int.37) or "Any time that your ambassador [a manager you have sent to speak to the level above you] doesn't have a great 
outing with the people above there is always some reflection on you." (TM, int.37). Second, it could lead to a loss of face for the SM, as SM1 explains:

[Having JM1 in the team] It meant that I never really knew what was going on, and therefore, at times you felt vulnerable because there was information that everybody would think you knew, that you should know, that I didn't know. And so ... Periodically, we'd talk it through. I know JM1 got very upset, I got cross and upset. (SM1, int.36)

Whilst at the beginning of the implementation, the pressure was such that people were too focused on the task, rather than on particular individual relationships, however later at Phase 2, when pressure eased off, as change was being implemented successfully, some leadership relationships broke:

"For a long time, I just moved to accept it, because there's too many other things I had to worry about. ... It took a long time to eventually had to say to him: 'I know [JM1] is your friend, but it's not working'." (SM1, int.36) Or,

"My worry is that JM4 was not able to rise up to the role, but on the other hand TM recommended him ... So I chose to invest in JM4, but when things went not well later [in the implementation of 'Shift'], I had to[push him out the team], it was not easy. But I couldn't ignore what I was hearing about him..." (SM4, int.32).

Further, as the relationship between TM and JM7 intensified during the implementation, SM7 started to look for alternative roles around MoneyManager, hence SM7 lost control on meaning and role:

SM7 would have been concerned about JM7's elevation in terms of looking what the future looks like [after 'Shift']. So as SM7 moves stage left, potentially to do his role outside of our, of our function- ... now that structure is being decided by JM7." (TM, int.17)

Free skip level leadership unsettled formal leadership relationships. When sensebreaking occurred this caused a loss of the mediating role for the SM, and disrupted their sense of self as leaders. However other forms of skip level leadership were acceptable, as they ultimately complied with institutional and social norms, which protected the formal leadership relationships.

\section{THEME 3: Settling for the Illusion of Transparency (see more data in Table 3)}

However there were legitimate ways in which top and JM could communicate, I call these controlled skip level leadership, and they emerge from the data as collective and one-toone (see APPENDIX 2 for triangulation of data of this phenomenon). These led to a form of 
bounded sensebreaking, where by top and JMs had the illusion of increased transparency whilst a form of pragmatic ambiguity still existed, bounded by the control of the SM.

Controlled Skip level Leadership. Controlled skip level leadership took two forms, one to one and collective ${ }^{7}$. One to one controlled skip level leadership happened when the top and JM communicated directly under the auspices of the SM. Because of the motivational properties of exposure to the upper echelons SMs where kin to reward those JMs who they 'trusted' by 'elevating' them to speak directly with the TM. Like SM1 said, "I would then start creating opportunities for these persons [who do not have direct access to TM] to be exposed to TM", and similarly SM2 said that he had " elevated them [few JMs] in front of him [TM] for their own personal career benefit", similarly SM8 said that "There are also some other members of the team who are strong, and have real potential, and actually I would like to create more time for them to see TM". In this form of leadership the SMs knew when the junior and TM had interactions, the interactions where legitimated by functional purposes, and the SMs were kept informed. As SM1 tells me:

TM quite often will sit down with [one of my reports] and will talk about something, or will sit down, have a one to one with [JMa], sit down have a one to one with [JMb]. But they are subject matter experts, so there is a clear qualification, or legitimacy of that exchange, anyway, outside from the personal relationship. Also we seat together-... they'll discuss with me. (SM2; int.xx)

Therefore those who were trusted, or who were legitimated by their expertise, were allowed, and given the opportunity to speak to TM. In this case, the search for clarity in which a JM would engage with a TM was bounded by the trust built with the SM, to whom the JM would stay loyal.

The second form of controlled skip level leadership was the collective one. Collective skip level leadership dynamics reflected an institutional attempt to provide the JMs with greater transparency, through legitimate channels of communications with the upper

\footnotetext{
7 The full version of this paper includes triangulations of observations, documents and interviews to corroborate this form of skip level leadership
} 


\begin{tabular}{|c|c|}
\hline \multicolumn{2}{|r|}{$\begin{array}{c}\text { TABLE } 3 \\
\text { Data Supporting CONTROLLED Skip Level Leadership Dynamics }\end{array}$} \\
\hline Theme & Representative Quotes \\
\hline \multicolumn{2}{|r|}{ THEME 3: Settling for the Illusion of Transparency } \\
\hline $\begin{array}{l}\text { Controlled } \\
\text { Skip Level } \\
\text { Leadership }\end{array}$ & 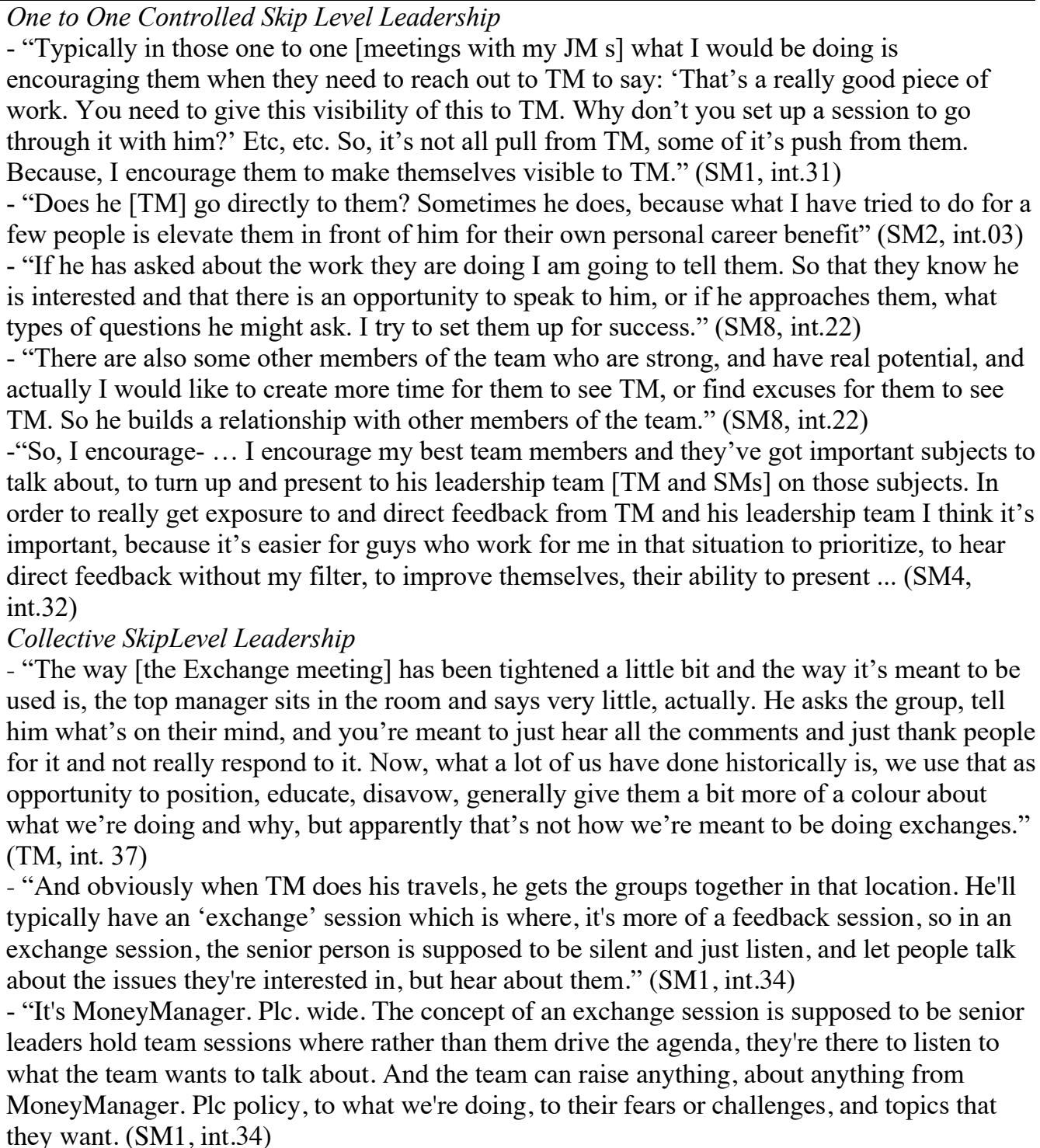 \\
\hline & $\begin{array}{l}\text { "For example he was out in Hong Kong a couple months ago and went to a guy that runs the } \\
\text { team there and started to give him all kinds of new things to do... And he called me up and } \\
\text { said TM is telling me to do this this and this... And I said great! Do it for TM... Because TM } \\
\text { at the end of the day is the guy that pays us. (SM2, int.03) } \\
\text { - "When they [my JMs] go and speak to TM they'll tell me. They'll literally tell me, because, } \\
\text { yeah, we've got to keep each other informed on what's going on." (SM8, int.22) } \\
\text { - "There's always a risk that the senior leader will do exactly that. Somebody will say } \\
\text { something that's a bit dumb and you can't let it slide, or even if it's not, you have to because } \\
\text { it's a public policy you have to be seen to be standing up for, but it's also the challenge of, it'll } \\
\text { cause a team often to react because it's top of mind, it's something that's a problem area, and } \\
\text { they'll think, I cannot believe that person just said that, before they've helped themselves. It's } \\
\text { almost instinctive. (TM, int.31) } \\
\text { - "Now, generally we [senior management] get away with it [interrupting the junior mager], } \\
\text { which is why we got the rules and we all now play a little harder of a script, but the exchanges } \\
\text { are almost a bit staged now because we're trying to not interrupt, (TM, int.37) } \\
\text { - "Exchanges are a bit staged. Because you're trying to get people's voices heard. At the same } \\
\text { time, you're not using it as a fireside chat. Perhaps that's the better way of describing it.... A } \\
\text { fireside chat allows you an inner look into the true agenda. I think we blended the two." (TM, } \\
\text { int.40) }\end{array}$ \\
\hline
\end{tabular}


managers, without jeopardizing the formal leadership process. The main two tools to achieve this were the Town Halls, and Exchanges. Town Halls were top down collective meetings held quarterly, in which the TM would address 50-60 JMs in various departments; the presentation was highly scripted by the Head of Communication. I witnessed the TM preparing in advanced, and rehearsing. During the implementation Town Halls were mostly centered on updates about 'Shift', there was a short Q\&A at the end, which mostly centered on the clarification of technical points. Exchanges were also highly staged encounters. They were MoneyManager wide events, the HR department had scripted very tightly how they were supposed to be run:

“Skip level Exchanges - encourage leaders to host Exchanges with lower levels of employee groups' or In Exchange meetings ... the host manager should listen with an open mind and do very little talking. Answer any questions they can and note down those they can't. Record the key themes so they can add the discussion themes to the dedicated Exchange site following the meeting" (HR document)

In Exchanges a top manager met with a group of JMs, one skipped level below. They were designed to be without agenda for people at the bottom to feel free to speak up about any issue of interest. In short, through controlled skip level leadership JMs had exposure to the top manager, and his interpretation of events, however they were tightly bounded by social and institutional norms. JMs, albeit exposed to possible different interpretations of events, stayed tuned to the inter-relational clarity they had formed with the SM, reverting to the meaning created through formal leadership. They pragmatically decided to embrace ambiguity, surrendering the possibility of disrupting, or over-riding the inter-relational clarity with the SM.

Pragmatic Ambiguity. Pragmatic ambiguity was a 'political necessity' (Eisenberg, 1984:229; Giroux, 2006), as it allowed JMs to be exposed to different interpretations of events, yet also to 'fill in' the interpretations in a way that did not over-ride or disrupt the inter-relational clarity previously formed with the SM. The preservation of pragmatic ambiguity, was a relational practice, that the JMs, and managers in more senior positions did together, by 
creating the conditions for bounded sensebreaking. This was a process through which individuals had the opportunity to engage in sensebreaking, however they self-censored and stayed short of disrupting or over-riding meanings of their leaders, in virtue of social and institutional norms. This happened as JMs observed their leaders, and reacted to what was acceptable to say or what was not. For example, in one to one controlled skip level leadership, the SM was not just recognized as a mediator of meanings, but also a mediator of relationships, as he was the sponsor of the relationship between top and JM. As such the JMs stayed loyal to him/her. In these cases possible equivocal interpretations of events were converted into pragmatic ambiguity, which still allowed JMs to stay loyal to the SM. As highlighted by SM8:

If they get an opportunity to speak with TM or if he approaches them, the types of questions he might ask, they tell me.... they don't want me to be surprised. One of the things I tell to them frequently is: 'If you've got bad news, let me know. What I don't want to do is find it out to somebody else or find out later in the day. The earlier I know, the better'." (SM8., int.33)

In Exchanges JMs found it more acceptable to speak about 'collective' viewpoints, about challenges 'they face together', with their managers too. In Exchanges people selfcensored, paid attention to the TM feedback, and reacted to his body language, and the body language of other more SMs in the room. When I enquired with a JM why he didn't speak much in an Exchange I had observed he articulated how he was happy to let more senior people than him, to speak on his behalf:

As much as exchange meetings is a place where you can say what you need to say, but at the same time $I$ do not think it is constructive to just starting to talk about any topic. It'll have to be collective [i.e. not personal], otherwise you would run out of time. So what is important is to pass the message as much as we can, in the most constructive way so that it triggers a discussion or an action to be undertaken. But if that's done, then we are happy that way. We are talking about challenges that we face all together" (JM, int.42)

After all, Exchanges had been designed to allow sensebreaking, i.e. they were explicitly described as a safe forum, where people had the opportunity to bring up issues, or challenges to the way things were. In Exchange meetings there was not set agenda:'In Exchange meetings ... the host manager should listen with an open mind and do very little talking' (HR Description of Exchanges, doc.34). However the mere presence of the TM, and other line 
managers in the room, made the JMs tune into what they considered was pragmatic meanings, i.e. acceptable in virtue of the boundaries created by those in higher levels of authority. These boundaries were made explicit during these meetings, as top manger couldn't hide their opinion about what had been said:

\footnotetext{
"But whilst exchanges are there to encourage voice, they can actually deter voice... It's very easy to do. Particularly- I went into one of these exchanges. I was a bit grumpy, and these were my own people [JMs]. It was a time that I felt that some of them were just not stepping up. We had two individuals in the room who are future talent, so I have high expectations of their talent, and they went off on a whinge. I was so bored, it was like when your children just push you one too far, they whinge. At that point, that got eviscerated [expressed by me]. Of course, it shut the entire room. So it's actually, you have to be very, very disciplined doing those. Otherwise, you will absolutely suppress." (TM1, int.37) Or,

"One of them made a statement on a perspective, and it clearly pressed all the wrong buttons ... You could see the [top manger] go: "You just cannot say that. What you just said there is such a-, I have to respond to that statement", You know." (JM, int.41)
}

Therefore the TM and JMs meaning making, during collective skip level dynamics, was characterized by bounded sensebreaking activities. Where attempts to over-ride, or disrupt existing meanings were made, but where effectively every meaning that had the potential of being disruptive was deemed unsafe, or too risky. In short, through the process of controlled skip level leadership, the managers and the institution itself attempted to create legitimate channels for the creation of transparency, but social and institutional norms bounded the JMs to a form of pragmatic ambiguity, which only created the illusion of having achieved greater transparency.

\section{DISCUSSION AND CONCLUSION}

This paper ultimately illuminates a micro perspective of how meanings are constructed during change, by zooming into the leadership relationships between TM, SMs and JMs in the same team, adding to research on sensemaking during change (Balogun et al, 2015) and to the scant skip level leadership literature (Detert \& Treviño, 2010). By considering the accounts of managers from their perspective of leaders and followers, and tracking how they construct meaning during change, I have elaborated theory around three routes by which meaning making and leadership interact in the interplay between ambiguity and search for transparency. These dynamics are: a formal one dominated by hierarchical 
leadership, a free skip level one, and a controlled skip level one. This elaboration has implications for understanding core assumptions about how managers in the position of linking pins (Likert, 1961, 1967) construct multiple dyadic leadership relationships with more powerful and less powerful others, how these interconnected relationships interact with each other during change, and how meaning making dynamics are affected by these multilevel relational exchanges. The interactions of the formal and skip level leadership dynamics illuminate some of the core reasons why in organizations ambiguity prevails on transparency.

Differently from the great part of research on leadership, this research uses a multilevel and temporal lens, focusing on the temporal evolution of leadership relationships across the hierarchy (Fairhurst, 2016). In doing so, it moves beyond the dominant lens used to study leadership, which has been individual, cognitive, and variable analytic (Fairhurtst \& Uhl-Bien, 2012; Fairhurst, 2016), and analyses relational dynamics and discourses. The multilevel view allows considering managers in their roles as leaders and followers concurrently; allowing the analysis to move beyond heroic models of leadership (Alvesson \&Wilmott, 2002), as well as the marginalization of the study of followership (Uhl-Bien, et al. 2014). The temporal approach helps to surpass a " focus on an individual's reading of the relationship as if there were a single relational reality" (Fairhurst, 2016:497; Sparrowe and Emery, 2015). Just by increasing the unit of analysis from a dyad to three individuals connected in a chain of authority, in which the individual in the middle is caught concurrently participating to two dyads (Likert, 1961; 1967), we attain a more complex picture of how managers construct leadership exchanges during change from a perspective of the coenactment of the two roles, as leaders and followers. Indeed, the accounts of the informants depict how during the implementation of change, traditionally studied leader-follower dyadic relationships have an effect on the variance of multilevel relationships, as epitomized by the statement of one of my informants: "I mean, you could read all the theory in the world about 
how to be a good leader of JM1, but you couldn't be a good leader of JM1, because she had the interaction with TM" (SM1, int.37). In short, this study brings to our attention a set of relationship almost entirely forgotten by the leadership literature: skip level relationships. The accounts of leadership, as well as the temporality of the dynamics, reveal that when individuals lower and higher in the organization enter in a direct and continuous, leadership exchange this can unsettles the formal hierarchical relationships, possibly to breaking point, as the SMs loses influence on the other two relationships. The temporal stretch of this study allows us to notice that all the free skip level leadership relationships did not exist any longer in Phase 2, as either the junior or the SMs had left the team.

Hence, whilst in dyadic leader-follower studies transparency might look as a possibility, it looks almost as utopic when considering multilevel relational dynamics in which a manager intermediates relationships and meanings. The impossibility of transparency is directly linked to the difficulty of skip level relationships. Leadership relationship as are therefore caged by the forces of bureaucracy. The study contributes to the theorization of a more multifaceted, less heroic side of managers as leaders. Their vulnerability is rooted on their efforts to engage and juggle in multiple upward and downward sensegiving and sensemaking efforts. The accounts of my informants reveal how SMs, embodying at the same time the role of leader and follower, operate as clearing houses of meanings, as they are at the epicenter of the downward and upward flows of sensegiving and sensemaking. As a result, the discourses of leadership and meaning construction highlight the importance that personal mediation of meanings has, for SMs, in creating own 'new' version of events, to pass down to their departments: "I want to keep people focused. So I don't always share everything with them" (SM2, int. 03) or "I think successful leaders are about telling stories" (SM2, int.02), or "I have to take ownership of what he [manager above] has asked me to do and make it mine. That's an act of leadership." (JM4, int. 09). The role of mediator emerges as tightly coupled to 
the role of leader.

Being a mediator of meanings emerges in this study as an important part of the SMs identity as leaders (i.e. their 'self-referential description that provides contextually appropriate answers to the question "Who am I?"; Ashforth, Harrison \& Corley, 2008:27). Identity is important, to help them situate themselves in the complex hierarchical context. It provides them with a set of cognition, affects and behaviour that allow them to navigate the multilevel relationships (Ibarra, Whittington, Petriglieri, 2014). When top and JM engage in free skip level leadership, this identity becomes under threat. Not just because they might construct different meaning of events, but precisely because the identity of SMs as clearing house of meanings, as mediators, is under threat. Because mediation is such an important part of who they are, then: who are they if they cannot mediate anymore? In this case, sensebreaking doesn't just entail, reframing, changing, or unmasking the elaboration of meanings controlled by the SM, it also entails disrupting their sense of self (Pratt, 2000) as leaders.

SMs, therefore, see their ability to mediate, as core to their role in the organization and when sensebreaking occurs their experience an identity void (Pratt, 2000). It is recognized that 'identity voids are often filled with anxiety and hope' (Ibarra, et al., 2014:290), this is reflected by the discourses of managers that were dis-intermediated through free skip level leadership as they told me of how 'anxious', 'cross', vulnerable', and 'upset' they felt. In short, whilst free skip level leadership generates greater transparency by providing junior and TM with a clearer communication channel, the cost is to unsettle the SM, who feels their role as mediator, and their self-concept as leader, is threatened. That might be why free skip level leadership creates instability, and at Phase 2 all the free skip level relationships had reverted to formal leadership, as the JM or SM left the team. Therefore, in attempting to create clarity, whilst holding control of the interpretation of meanings, SMs become dependent for their very existence on the conditions they claim they were attempting to change, i.e. ambiguity. 
Nonetheless, in search for greater clarity, the top and JMs demand channels that could provide opportunities to create greater transparency in communication. The composite accounts reveal how measures to ensure a controlled type of skip level communication arise in two ways. On one hand the organization itself puts in place a set of upward (skip level exchanges), and downward (town hall) meetings for direct communication. On the other hand, SMs themselves sponsor forms of controlled skip level leadership, which promote direct communication between junior and top manager. What comes to exist in this way is a form of pragmatic ambiguity, which is a 'political necessity' (Eisenberg, 1984:229; Giroux, 2006), as it allows managers to search for transparency in a controlled way, so that they exercise a bounded form of sensebreaking. This is a tactful tentative over-riding of meanings, which never quite gets to change or disrupt them, as JMs self-censor, as they know that destroying meaning is too risky and could backfire. This only gives the illusion of greater transparency; here the SM self-concept as leader is not threatened, as he/she retain the last say on how to implement change.

\section{Limitations and Direction for Future Research}

This research has many limitations, first it is bound to time and context, therefore it is impossible to generalize these findings, however it gives rise to possible new hypotheses that could be tested through quantitative methods, and therefore contribute further to extant leadership research to explore dyadic linkages, as suggested by Sparrowe \& Emery (2015:296). Further it relies on an individual case study, although studied through a longitudinal approach. It would be advisable to explore if these findings still stand in different contexts. 


\section{REFERENCES}

Alvesson, M., \& Willmott, H. (2002). Identity regulation as organizational control: Producing the appropriate individual. Journal of management studies, 39(5), 619-644.

Ashby, S. (2011). Risk management and the global banking crisis: Lessons for insurance solvency regulation. The Geneva Papers on Risk and Insurance-Issues and Practice, 36(3), 330-347

Ashforth, B. E., Harrison, S. H., \& Corley, K. G. (2008). Identification in organizations: An examination of four fundamental questions. Journal of management, 34(3), 325-374.

Balogun, J., Bartunek, J. M., \& Do, B. (2015). Senior Managers' Sensemaking and Responses to Strategic Change. Organization Science, 26(4), 960-979.

Corbin, J., and Strauss, A. (1990) Grounded Theory Research: Procedures, Canons, and Evaluative Criteria. Qualitative Sociology, 13, 1. 3-21.

Corley, K. G., \& Gioia, D. A. (2004). Identity ambiguity and change in the wake of a corporate spinoff. Administrative Science Quarterly, 49(2), 173-208.

DeRue, D. S., \& Ashford, S. J. (2010). Who Will Lead And Who Will Follow? A Social Process Of Leadership Identity Construction In Organizations. Academy Of Management Review, 35(4), 627-647.

Detert, J. R., \& Treviño, L. K. (2010). Speaking up to higher-ups: How supervisors and skip level leaders influence employee voice. Organization Science, 21(1), 249-270.

Eisenberg, E. M. 1984. Ambiguity as strategy in organizational communication. Communication Monographs, 51: 227-243

Fairhurst, G. T. (2016). Leadership Process in Langley, A., \& Tsoukas, H. (Eds.).The Sage handbook of process organization studies, 497-511

Fairhurst, G. T., \& Grant, D. (2010). The social construction of leadership: A sailing guide. Management Communication Quarterly, 24(2), 171-210.

Fairhurst, G. T., \& Uhl-Bien, M. (2012). Organizational discourse analysis (ODA): Examining leadership as a relational process. The Leadership Quarterly, 23(6), 1043-1062

Gardner, W. L., Avolio, B. J., Luthans, F., May, D. R., \& Walumbwa, F. (2005). "Can you see the real me?" A self-based model of authentic leader and follower development. The Leadership Quarterly, 16(3), 343-372

Gioia, D. A. and Chittipeddi, K. (1991). 'Sensemaking and sensegiving in strategic change initiation'. Strategic Management Journal, 12, 433-48.

Giroux, H. (2006). 'It was such a handy term': management fashions and pragmatic ambiguity. Journal of management studies, 43(6), 1227-1260.

Glaser, B., \& Strauss, A. (1967). Grounded theory: The discovery of grounded theory. Sociology The Journal Of The British Sociological Association, 12, 27-49. 
Graen, G. B., \& Uhl-Bien, M. (1995). Relationship-based approach to leadership: Development of leader-member exchange (LMX) theory of leadership over 25 years: Applying a multi-level multi-domain perspective. The Leadership Quarterly, 6(2), 219-247.

Harding, N., Lee, H., \& Ford, J. 2014. Who is 'the middle manager'?. Human Relations, 67(10):12131237

Huy, Q. N. (2011). How middle managers' group-focus emotions and social identities influence strategy implementation. Strategic Management Journal, 32(13), 1387-1410.

Huy, Q. N., Corely, K. G., \& Kraatz, M. S. (2014). From support to mutiny: 'Shift'ing legitimacy judgments and emotional reactions impacting the implementation of radical change. Academy Of Management Journal, 57(6),

Ibarra, H., Wittman, S., Petriglieri, G., \& Day, D. V. (2014). 14 Leadership and Identity: An Examination of Three Theories and New Research Directions. The Oxford handbook of leadership and organizations, 285.

Knorr Cetina, K., \& Preda, A. (2006). The sociology of financial markets. Oxford University Press.

Lewis, M. W. (2000). Exploring paradox: Toward a more comprehensive guide. Academy of Management review, 25(4), 760-776.

Likert, R. (1967). The human organization: Its management and values.

Mantere, S., Schildt, H. A., \& Sillince, J. A. (2012). Reversal of strategic change. Academy of Management Journal, 55(1), 172-196.

Norman, S. M., Avolio, B. J., \& Luthans, F. (2010). The impact of positivity and transparency on trust in leaders and their perceived effectiveness. The Leadership Quarterly, 21(3), 350-364.

Pagano, B., \& Pagano, E. (2004). The transparency edge: How credibility can make or break you in business. McGraw Hill Professional

Pratt, M. G. (2000). The good, the bad, and the ambivalent: Managing identification among Amway distributors. Administrative Science Quarterly, 45(3), 456-493.

Rouleau, L. (2005) Micro-Practices of Strategic Sensemaking and Sensegiving: How Middle Managers Interpret and Sell Change Every Day. Journal of management Studies, 42:7, 00222380

Rouleau, L., \& Balogun, J. (2011). Middle Managers, Strategic Sensemaking, and Discursive Competence. Journal Of Management Studies, 48(5), 953-983

Shamir, B., \& Eilam, G. (2005). "What's your story?” A life-stories approach to authentic leadership development. The leadership quarterly, 16(3), 395-417.

Schnackenberg, A. K., \& Tomlinson, E. C. (2016). Organizational transparency: A new perspective on managing trust in organization-stakeholder relationships. Journal of Management, 42(7), 17841810.

Sonenshein S (2010) We're changing or are we?: Untangling the role of progressive, regressive and stability narratives during strategic change implementation. Acad. Management. J. 53(3):477- 
512.

Sparrowe, R. T., \& Emery, C. (2015). Tracing Structure, Tie Strength, and Cognitive Networks in LMXTheory. The Oxford handbook of leader-member exchange, 293.

Sparrowe, R. T. (2005). Authentic leadership and the narrative self. The leadership quarterly, 16(3), 419-439.

Suddaby, R. (2006). From the editors: What grounded theory is not. Academy of management journal, 49(4), 633-642.

Uhl-Bien, M., \& Ospina, S. (Eds.). (2012). Advancing relational leadership research: A dialogue among perspectives. Charlotte, NC: Information Age.

Uhl-Bien, Mary (2006). "Relational Leadership Theory: Exploring the social processes of leadership and organizing.". The Leadership quarterly (1048-9843), 17 (6), p. 654.

Uhl-Bien, M., Riggio, R. E., Lowe, K. B., \& Carsten, M. K. (2014). Followership theory: A review and research agenda. Leadership Quarterly, 25(1), 83-104.

Vogelgesang, G. R., Leroy, H., \& Avolio, B. J. (2013). The mediating effects of leader integrity with transparency in communication and work engagement/performance. The Leadership Quarterly, 24(3), 405-413

Vogelgesang, G. R., \& Lester, P. B. (2009). How leaders can get results by laying it on the line.

Organizational Dynamics, 38( 4), 252-260

Weick, K. E. 1995. Sensemaking in Organizations. Sage, Thousand Oaks, CA.

Weick, K. (2007). Romancing, Following and Sensemaking: James Meindl's Legacy. In B. Shamir, R. Pillai, M. C. Bligh, \& M. Uhl-Bien (Eds.), Follower - centered perspectives on leadership: A tribute to the memory of James R. Meindl (pp. 187-209). Greenwich, CT: Information Age

Weick, K. E., Sutcliffe, K. M., \& Obstfeld, D. (2005). Organizing and the Process of Sensemaking. Organization Science, 16(4), 409-421. 


\section{APPENDIX 1 \\ Coding and Triangulation of Data Sources for Practices of FREE Skip Level Leadership}

\section{Formal Interviews:}

'So TM does not have a hierarchical approach [to our relationship]. If he thinks there is something that he believes is in SM1's remit, he will send it to her. If he feels that this is straight away to my remit he will send it to me ... And he has done a series of things already to make sure that the information flows doesn't stop [at $\mathrm{SM} 1]$, so for example he told all of his direct reports that anything relating to finance et cetera should be solved directly by me.' (JM1, int.05)

'I'm going out for a beer with him next week just a pair of us.' (JM4, int.09)

'If you sat on the same floor and you bump into him [TM] in a lift, some mornings, or into a coffee machine, um, you build a relationship.' (JM2, int.08)

'I sat next to him [TM] for dinner [at our team off-site] and had a quite good evening chatting to him when he was quite new ... He then approached me for a couple of opportunities in Hong Kong.' (JM3, int.08)

'We meet every sounday morning by the pitch, our daughter play lacrosse togehther' (JM4, int.xx)

'When he came over to Hong Kong he popped by my desk, and we had a series of direct conversations on what we are doing over here for the implementation, and what we should expect coming in the next months, he told me about what he wants to achieve, like, um, the big picture' (JM10, int.27)

' Yes I saw him when he came last month [in New York City], we had a coffee together, but not direct [foormal] one-to-ones. ... But, of course when he comes I, um, I talk to him, he is a nice man' (JM9, int.24)

'Because TM has people he brings in, and he gives to people [SMn], but he's still really giving and maintaining that direct relationship. . So, you know- So I'm interviewing someone today, right? [A] mate of TM's. For a job that will report to me or to SM2.' (SM1, int.36)

Congruent Behaviour: As highlighted in figure.3 TM has reciprocal leadership exchanges with three junior managers (JM1, JM4 and JM7). TM trusts these managers, he looks out for them, they confide in him, beyond confiding in their SM. TM hired JM4, and JM1 as they used to work together at FinComp (another financial institution). Beyond these reciprocal relationships other junior managers pop by top manager's desk informally for direct communication; junior managers stopped at coffee machine to discuss with top manager directly; junior manager use off-site opportunities to speak directly to junior manager; top manager goes directly to those junior managers on the same floor when he need to quickly check some information; top manager suggests possible new hires of junior managers to his senior managers; top manager and junior manager meet socially outside work. In the Private Client Group, a site far from head office, and far from the top manager, the exposure to TM was rather reduced, and the relationships between junior and senior managers were more relaxed and informal. In these locations it was more difficult for Free One-to-One skip level leadership to take place. TM's reciprocal leadership relationships with junior managers (JM1, JM4 and JM7) all happened in the head quarter, and all working on the same floor as TM.

Informal Conversation: Managers speak about approaching their boss' boss on occasions. They use expression as us 'you can walk up to his desk and talk to him', 'if you see him around, you can have a chat', 'I like working in this team because he is a nice manager, he is accessible', 'any one can go up and talk to him', 'I have to be careful but I can informally talk to him', 'it's not something I'll do everyday, but occasionally I can [talk to my boss'boss]'; '[TM] has a horrible memory for names, so he only goes to people in lower levels that he knows well'; 'of course I go up to him if I need to know'.

People in other location than central office are looking forward to top manager to visit to have direct exposure to him, they use expression like: 'he is coming next week and I will try to approach him', ' we do not have direct communication, but he is coming, so will see', ' it would be much better if I was seating there, wouldn't it, but we are now in this other building'.

Observations and Formal Meetings: junior manager and top manager schedule one-to-one meetings without senior manager present; TM asks a junior manager to take minutes of GORB meeting, and therefore this JM controls the narrative of what is recorded. The top manager seats on a separate desk on one side of a huge open plan office, he does not seat in an enclosed space so everyone can approach him.

Casual Informal Observations: managers on open floor are informal in their exchanges, away from formal leadership relationships; those who seat together develop informal practices of exchange, buy coffee for each other and top manager regardless of hierarchical order. 
Archival Data: Some junior managers send direct emails to the top manager without copying in the senior manager in the 'cc:' field. I viewed some of these e-mails from JM1 and JM4, but then heard of these practices from others in the team. The top manager occasionally sends e-mails to junior managers without copying the senior manager in the 'cc' field. In these occasions the TM told me he expects the junior managers to keep his

APPENDIX 2

Coding and Triangulation of Data Sources for Practices of CONTROLLED Skip Level Leadership

\section{One-to-one Practices}

\section{Formal Interviews}

Controlled One-to-One Skip Level Leadership:

'TM was out in Hong Kong a couple months ago and went to a guy that runs the team there [JMH] and started to give him all kinds of new things to do... And [JMH] called me up and said TM is telling me to do this this and this... And I said great! Do it for TM... Because TM at the end of the day is the guy that pays us. It's really important to give my guys exposure to TM because at the end of the day when we go through and we sort out the bonus pool and the ratings market is the one making the final calling, and sometimes other writers and staff.' (SM2, int.03)

'What I'm also doing is, there are other members of my team who aren't as strong as JM8 yet, but have got real potential. So, I'm gradually trying to, I'm not trying to, I'm negotiating more time for them to see TM or find excuses for them to go and talk to him about things.' (SM8, int.33)

'TM questioned what people that work for me do. [For example he questioned] JMn who works for me. I couldn't find the words to look unemotional or protective of what she does for me. Then I was doing her a disservice because people thought oh, they are such good friends that she wants just to keep her... Then I gave JMn exposure to TM, eventually things changed" (SM1, int.36)

\section{Congruent Behaviour:}

Controlled One to One Skip Level Leadership: I witnessed at least 3 instances in which junior managers approach the TM desk informally they did it with deference, awaiting for him to raise his gaze before talking to him, often on their way back to their desk they stopped by at the senior manager desk by telling them of the outcome. Junior manager are eager to be exposed to top manager, and they see it as a coveted reward. 'I will spend more time with him as our relationships develop, may be when [SM2] is on holiday, he will come to ask me for information'.

\section{Informal Conversation:}

Controlled One- to-One: 'So TM would go up to Martin (JM) and ask him a question directly or there is a chap called Andrew (JM), if Martin isn't there he would go to Andrew, um, or pick up the phone and ask lower level people, but there is a specific reason he goes to them, they don't go via the [senior manager], but the senior manager knows because of that specific reason.' Other informal conversation: 'yes he comes to me, but I always check back with [SM]', 'ah yes once he came over, we had a chat, I told SM8 afterwards', 'last month when he $[\mathrm{TM}]$ came over, he asked me to be in charge of one small project, it was about coordinating a regulatory change for the new risk framework at local level, so I wrote all the e-mails to TM, but I was putting SM10 in cc'; 'When he was in Asia he told them a specific thing, which got fed back to SM3, and was completely different to what she had told her people in Asia. So SM3 had to put it in writing, because he [TM] had gone there had a meeting and the told them something which was not quite right. So she sent them all an e-mail to reiterate her version [laugh]';

Observations and Formal Meetings: Senior managers send junior managers, they particularly trust, to represent them in important meetings. The junior managers are exposed to TM and other senior managers in this occasion as ambassadors or agents of the senior manager. So despite there is a direct leadership exchange TM$\mathrm{JMn}$, this is under the patronage of the senior manager. During conference calls and GORB meetings I have witnessed junior managers interventions on behalf of their senior managers. I cross-checked with the Senior managers afterward whether they knew of these interventions, and they did.

Casual Informal Observations: TM is eager to speak to junior managers and influence them; he then leaves it up to each junior manager to clear the formal leadership relationship with their senior managers. In this case, 
most junior managers would revert back to their senior managers, to clear the leadership exchange they had with TM.

\section{Archival Data:}

Controlled One-to-One: Absent, given the informal nature of these relationships there is no documentation.

\section{Collective Practices}

\section{Formal Interview:}

Town Hall: 'And that's the Town Hall, I guess, that's [where TM speaks directly to] the top 50 or 60 [JMs] in the function. I'm really trying to focus on them owning the change, because I think, you know, their ownership of the programme is difficult, I think... so it's really about promoting their [JMs] role, their need to be advocates, how TM sees their mandate, what he expects from them in terms of their focus and their priorities' (SM1, int.31)

Exchanges: 'I mean, the exchange is a feedback session, so that's bottom up. So, that should be feedback coming up from your team. (SM1, int.31).

I mean for sometime now we're trying to engineer something that can be fed back on the way back up to the $\mathrm{CEO}$ et cetera, these are the Exchanges. Where I go in and listen to the lower level population that report to my [senior managers].' (TM, int.37).

\section{Congruent Behaviour:}

Town Hall: TM prepares well in advance he rehearses the content mentally, by spending time going through the presentation at his desk. TM sees the Town Hall as a staged act, it is formal act through which he messages the strategy to a large chunk of his population globally. It is a place where he can reach a broader part of his team end envision what the operational risk function is going to be like during and after Metamorphosis. He uses high level abstract language 'my desire is for us to spend quality time with control officers, and provide them with leadership, rather than to do their job for them'. TM uses town hall as a team building activity, he sometimes invites senior guest speakers from other departments as well, so his people can receive a direct illustration of . Exchanges: TM finds exchanges frustrating, because he has to listen to people complaints without responding spontaneously: Exchanges are seen as difficult from the TM as he finds it difficult to keep quite when he hears remarks from the lower level management. TM uses exchanges as talent spotting contests, in which he forms opinion on the emergent talent. Because of the huge exposure that junior managers have to the TM, they do not often speak freely. ' 'You're trying to get people's voices heard. At the same time, you're not using it as a fireside chat. So people don't really say what they think. 'I think exchanges are good for my people to have exposure to TM'. ' Once I heard of this guy at the top he got so angry and frustrated during this exchange (laughs), someone said something dumb and he couldn't just keep quite about it'. When TM attend an exchange meeting he cannot refrain from speaking a lot and control the agenda. During Exchanges people speak positively about their managers, highlighting what a good jb they have done. People tiptoe around difficult issues, there is snarling joke abou the UK political landscape, which dies immediately without follow up.

\section{Informal Conversation:}

Town Hall: The Town Hall was something people where eager to join, it was considered informational. But it was also considered a bit staged, and scripted: 'As communication manager I prepare the Town Hall, I mean- the presentation for the Town Hall, and organize what TM says, in coordination with him, of course'. 'In July I organized a two day offsite for the level four (junior managers), where TM was giving them a speech, it was involved with the Metamorphosis, but also he was talking to them about the future, what is going to happen, what's the plan. I did it with [communication manager], of course because she was preparing the slides.'

Exchanges: 'they moved to London Bridge office now, so there is disconnect, so it is important that TM has [exchange] sessions to hear from them'; ' He is now going down one level with the exchanges, in July they had a one day in which he went there and for one or two hours he sat down with the lower level managers'. ' he listens to them and they speak to him', 'we are arranging another exchange at the end of the year as the Private Client Business is in that building in Mayfair', 'he wouldn't normally meet them up, because they are in a different building so TM has to be over there'; ' look, this was the first time this happened. I had never had A. a one to one with my global head of anything before and B. I had never sat on an open session on a town hall if you like with my global head [TM] and there isn't, there isn't an agenda, there isn't somebody, he's not there deliberately there to tell me something.' The presence of an authority figure like the TM makes everyone rather formal, measured, and not spontaneous in the way they interact. The most spontaneous people are the more senior junior managers. 


\section{Observation and Formal Meetings}

Town Hall: Town Hall are staged events, in which TM addresses an audience of 50-60 junior managers, additionally to his senior managers. Junior and senior managers all attend together. His presentation is scripted, and prepared in advance from the head of communication. The messaging is agreed with the different Senior Managers before it is put out. However the TM occasionally clarifies and explains things according to his personal interpretations of event, by putting thing 'in his own words'. The Senior Managers are fast in picking on these cues, and use these interpretations to integrate their own interpretations to their people. Junior managers like attending town halls (either in person of via conference call) although they consider them formal events, where only the official version of events is spoken about. Few told me that aside from the town hall they use their informal networks to understand what the 'real story' is.

Exchanges: Exchanges are formally organized meetings where the employees are supposed to feel they can speak about issues from a bottom up perspective. They are supposed to be bottom-up driven, and without an informal agenda. However from my observation the agenda develops very quickly, as the attendees respond to verbal and not verbal queues of the TM in the room. Therefore whilst Exchanges are without an 'explicit agenda', people in the room are always looking for the 'implicit agenda' of the top manager. In fact the top manager with verbal and non verbal language validates what people are saying or not saying. From my observations, one of the more junior people in the room had his line manager present, and he never spoke during the exchange. He then told me: 'there was no need for me to say anything on that topic, because my boss was already raising these points'.

Casual on-site observation: Given the formality of these events there are not casual observations on record.

\section{Archival Data:}

Town Hall: Meetings are very 'formal and staged', schedules are precise and rigid. These are the meetings when a level 2 manager faces his 'broader manager population'. The TM follows a scripted presentation prepared by the Head of Communication. The timing is calculated clearly at different stages of the script. Town Hall presentations are designed to create consistency in top-down messaging to the broader operational risk team population.

Exchange Rules: HR Description of Exchange Meetings: 'Exchange meetings are informal get-togethers amongst employees and their managers... In traditional business meetings managers do most of the talking, whilst exchanges recognize it's just as important that managers listen, understand and learn about what matters to employees.' 'In Exchange meetings ... the host manager should listen with an open mind and do very little talking. Answer any questions they can and note down those they can't. Record the key themes so they can add the discussion themes to the dedicated Exchange site following the meeting.' "There are different types of exchanges. ... Skip level Exchanges - encourage leaders to host Exchanges with lower levels of employee groups'. 'Topics/Themes are noted and the feeling around that particular topic are recorded on the Exchange Share Point Site - up to eight topics/themes can be recorded ' 